\title{
SYNOVIAL SCHISTOSOMIASIS OF THE HIP
}

\author{
OMAR AL BAZ FACHARTZ, V. KUMAR, MOHIUDDIN AL HILOU
}

From King Fahd Hospital, Jeddah, Saudi Arabia

\begin{abstract}
Schistosomiasis is a common parasitic infestation in Egypt. We describe the case of a 24-year-old Egyptian man who presented with the signs of acute septic arthritis of the hip and in whom biopsy subsequently revealed schistosome ova in the synovium.
\end{abstract}

J Bone Joint Surg [ Br] 1993; 75-B:602-3.

Received 14 October 1992; Accepted 3 December 1992

Schistosomiasis (bilharziasis) is the group of diseases caused by trematodes of the genus Schistosoma. Man and other animals are definitive hosts and snails of various genera are the intermediate hosts.

In 1965, the World Health Organisation estimated that 180 to 200 million people were infected throughout the world. In Egypt alone, 37\% of the population are said to be infected and the number is believed to be growing (Manson-Bahr and Apted 1982).

\section{CASE REPORT}

A 25-year-old Egyptian man reported to the Emergency Room complaining of pain in his right hip for 12 days after a fall from a height of two metres. He was febrile and had tenderness but no swelling or redness over the front of the hip. The range of movement was restricted in all directions. The ESR was $68 \mathrm{~mm} / \mathrm{hr}$ and there was a leucocytosis of $17400 / \mathrm{mm}^{3}$. Radiographs showed loss of the joint space and an osteolytic lesion in the superior aspect of the femoral neck (Fig. 1). Needle aspiration produced $5 \mathrm{ml}$ of pus.

A course of cephradine was started and an arthrotomy was performed the same evening through an anterior approach. The inflamed joint was washed out with normal saline and closed over a drain. Subsequently, the wound healed but serosanguinous fluid continued to discharge from the drain site. The patient remained febrile and the ESR rose to $106 \mathrm{~mm} / \mathrm{hr}$. Cultures from the joint had produced no growth and blood cultures, urine and stool examinations were negative.

O. A. B. Fachartz, Chief Consultant Orthopaedic Surgeon

V. Kumar, FRCS Ed, Consultant Orthopaedic Surgeon

M. A. Hilou, MD(Paris), Orthopaedic Specialist

King Fahd Hospital, PO Box 50505, Jeddah 21463, Saudi Arabia.

Correspondence should be sent to Dr V. Kumar at PO Box 11608, Jeddah 21463, Saudi Arabia.

(C)1993 British Editorial Society of Bone and Joint Surgery $0301-620 \mathrm{X} / 93 / 4585 \$ 2.00$
After two weeks the discharge from the drain site produced a positive culture of Staphylococcus aureus. Fucidine and amikacin were added to the antibiotic treatment and the joint was again opened and irrigated. Pus taken at this operation was sterile, the patient's temperature settled and the white cell count diminished.

One week after the second exploration, however, febrile episodes $\left(39^{\circ} \mathrm{C}\right)$ recurred every second or third day, and sterile fluid continued to discharge, despite continued treatment with cephradine and Fucidine.

Bone scintigraphy showed an increased uptake in the acetabulum and the femoral neck which seemed to suggest avascular necrosis of the femoral head. CT showed osteolytic lesions in the femoral head and neck and also revealed calcified areas in the bladder wall, seminal vesicles, lower rectum and prostate. The Mantoux skin test was negative. The osteolytic lesion in the femoral neck was thought to be the focus of infection, and a further arthrotomy was planned.

Nineteen days after the second operation the joint was explored for a third time. The femoral head was

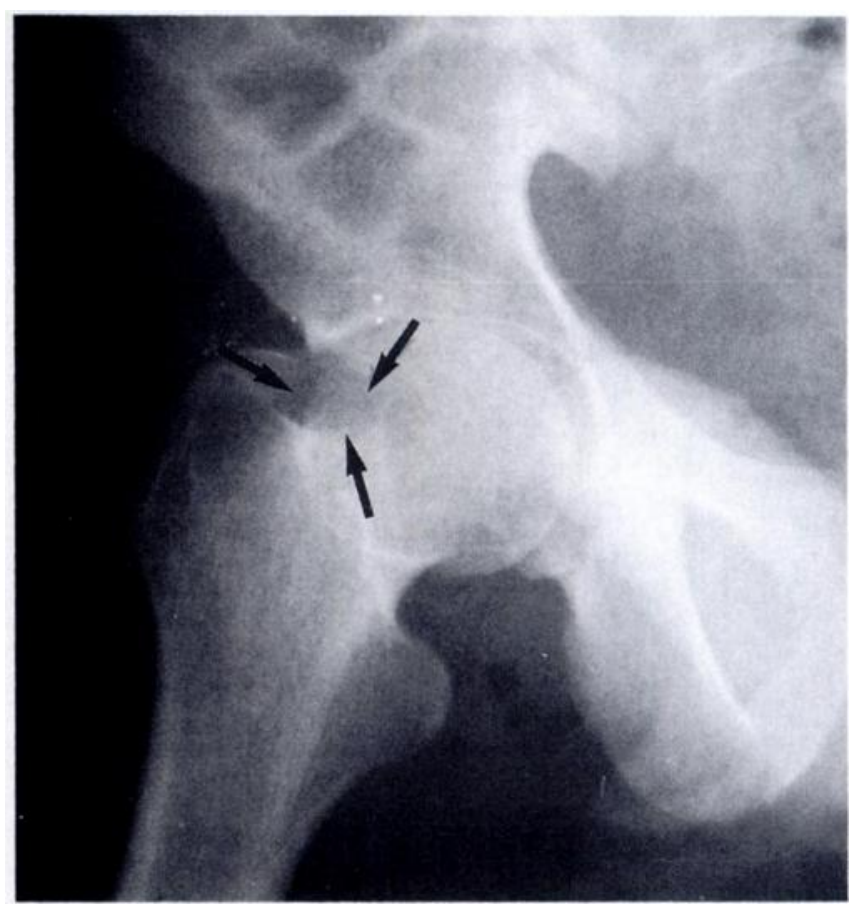

Fig. 1

Radiograph of the right hip on admission. There is an osteolytic lesion in the femoral neck (arrows). 


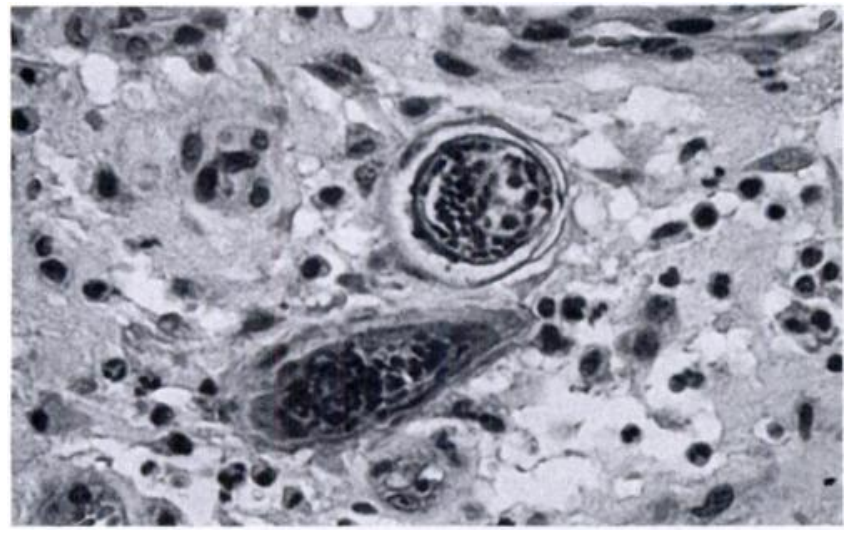

Fig. 2

Synovium showing mixed inflammatory cells and two schistosome ova, one cut transversely and the other longitudinally (haematoxylin and eosin $\times 200$ ).

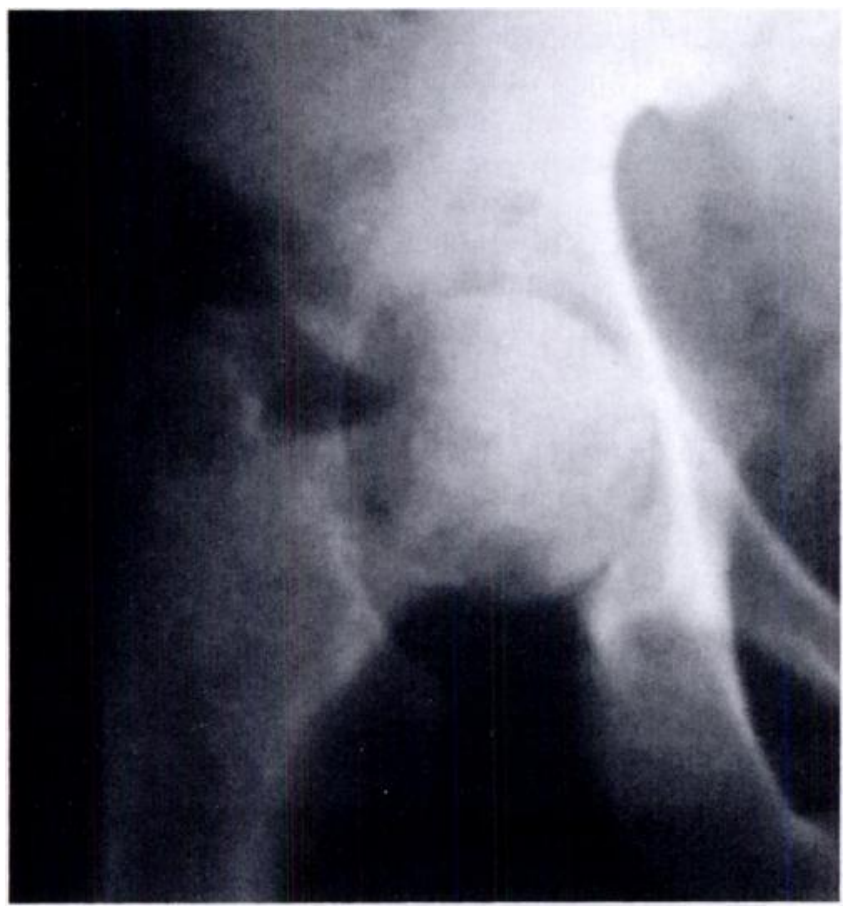

Fig. 3

At nine months the sclerotic area in the femoral neck shows signs of healing.

found to be completely devoid of articular cartilage with no inflammatory reaction in the exposed bone. There was no fluid in the joint cavity, and the synovitis had subsided although the joint capsule was thickened. A window was made in the anterior-inferior aspect of the neck of the femur to reveal a cavity surrounded by sclerotic bone. The cavity was curetted, bone and synovium were taken for biopsy, and the wound was irrigated and closed over a drain. Cephalosporin treatment was continued.

Sections of the synovium (Fig. 2) showed granulation tissue heavily infiltrated with acute inflammatory cells and schistosome ova. The femoral neck biopsy showed lamellar bone with empty lacunae. Praziquantel (Biltricide; Bayer) treatment for schistosomiasis was given as a single dose of four tablets. Postoperative recovery was satisfactory. The wound healed well and drainage from the joint had ceased when the patient was discharged, 19 days after the last operation. Examinations of the urine and stools on three consecutive days showed no sign of schistosomiasis. The intravenous pyelogram was normal but ultrasound examination of the abdomen showed a prominence of the periportal walls (fibrotic), borderline dilatation of the portal vein, a fibrotic liver, and splenomegaly.

At three-month follow-up the patient was well and had a nearly full range of hip movements which were nearly painless. At nine months he still had a good range of hip movements and had started weight-bearing on the right leg without crutches. The sclerotic area in the femoral neck showed signs of healing (Fig. 3).

\section{DISCUSSION}

Septic arthritis secondary to psoas abscess (Toren et al 1989), rheumatoid arthritis (Wohlgethan et al 1989), avascular necrosis of the hip (Phillips and Pottenger 1988), fungal infection (Cryptococcus neoformans) (Stead et al 1988), and Mycoplasma hominis infection (Kim 1988) have all been described but we have not found a previous report of synovial schistosomiasis. As this case shows it is very difficult to diagnose this parasitic infestation in synovium.

The diagnosis was made only by synovial biopsy and specific serological tests were not carried out since we did not suspect schistosomiasis. The case has taught us to have a high index of suspicion of other underlying disease when dealing with septic arthritis, especially if routine cultures are negative or the condition does not respond to the antibiotics appropriate for the cultured organisms (Kim 1988). In such cases synovial biopsy can be very helpful.

We wish to thank Dr John Amuesi, MRCPath (London), for the preparation of the histological slides.

No benefits in any form have been received or will be received from a commercial party related directly or indirectly to the subject of this article.

\section{REFERENCES}

Kim SK. Mycoplasma hominis: septic arthritis. Ann Plastic Surg 1988; 20:163-6.

Manson-Bahr PEC, Apted FIC, eds. Trematode infections: schistosomiasis. In: Manson's tropical diseases. Eighteenth ed. London: Ballière Tindall, 1982:206-41.

Phillips FM, Pottenger LA. Acute septic arthritis in chronic osteonecrosis of the hip. $J$ Rheumatol 1988 ; 15:1713-6.

Stead KJ, Klugman KP, Painter ML, Koornhof HJ. Septic arthritis due to cryptococcus neoformans. J Infect 1988; 17:139-45.

Toren A, Ganel A, Lotan D, Graif M. Delayed diagnosis of a primary psoas abscess mimicking septic arthritis of the hip. J Pediatr Surg $1989 ; 24: 227-8$.

Wohlgethan JR, Stilmant MM, Harris JM, Smith HR. Acute noninfectious arthritis of the hip in rheumatoid arthritis: synovial membrane findings. Ann Rhewm Dis 1989; 48:250-3. 